\title{
Characterisation of Adaptive Reuse Stakeholders and the Effectiveness of Collaborative Rationality Towards Building Resilient Urban Areas
}

\author{
Itohan Esther Aigwi ${ }^{1}$ (D) Robyn Phipps ${ }^{1} \cdot$ Jason Ingham $^{2} \cdot$ Olga Filippova $^{3}$
}

Published online: 22 February 2020

C) Springer Science+Business Media, LLC, part of Springer Nature 2020

\begin{abstract}
In an adaptive reuse decision-making setting, there is usually an occurrence of conflicting beliefs, opinions, interests, and resources among relevant stakeholders. Knowing who these stakeholders are and why, through a collaborative approach, will allow stakeholders with diverse interests regarding adaptive reuse to come together and participate either directly or indirectly in any stage of the decision-making process. This paper examines the usefulness of collaborative rationality among stakeholders involved in an adaptive reuse decision-making process. The specific objectives include: to characterise the stakeholders involved in an adaptive reuse decision-making process; and; investigate how their collaborative rationality can be effectively integrated into the adaptive reuse decision-making process. After a review of existing literature, four typical categories of stakeholders involved in an adaptive reuse decision-making process were identified: i) investors; ii) producers; iii) regulators; and iv) users. Also, the effectiveness of collaboration among the diverse stakeholders of an adaptive reuse decision-making process was validated using a focus group workshop to incorporate transparency, common goal, ideal speech, and consistency into the process. These findings imply that the active collaboration among characterised adaptive reuse stakeholders is important to mitigate the risk of manipulation of an adaptive reuse decision-making process, and, for policy makers to understand better the expectations and needs of the public, thereby, enhancing consents for optimal adaptive reuse decisions.
\end{abstract}

Keywords Collaboration · Adaptive reuse $\cdot$ Decision-making $\cdot$ Stakeholders

Itohan Esther Aigwi

i.aigwi@ massey.ac.nz

1 School of Built Environment, Massey University, Auckland, New Zealand

2 Department of Civil and Environmental Engineering, The University of Auckland, Auckland, New Zealand

3 Department of Property, The University of Auckland, Auckland, New Zealand 


\section{Introduction}

The characterisation of relevant stakeholders and the collaborative rationality that exists amongst them in a decision-making process is in due course, crucial to the successful execution of any sustainable development plan. In most adaptive reuse decision-making contexts, there is usually an occurrence of conflicting beliefs, opinions, interests, and resources among relevant stakeholders (Aigwi et al. 2019b). Hence, it would be beneficial to all participants involved in an adaptive reuse decision-making process, if they all understand who the other actors are, how their interests are interlinked, and how the collaborative approach functions (Innes and Booher 2010).

Collaborative approaches are established settings that allow stakeholders with diverse interests to come together and jointly participate in any stage of a decision-making process. Their participation in the decision-making process could be direct, indirect, formal or informal (Van Den Hove 2006). A decision-making process is collaboratively balanced when all stakeholders with various perspectives about a common problem engage in a head-on dialogue to jointly deliberate on the issue (Innes and Booher 2010). To introduce collaboration into a decision-making process, all stakeholders involved are entitled to express their opinions and be listened to, whether the views make sense or not. Techniques should be introduced into the decision-making process to jointly assure the comprehensibility, accuracy, and sincerity and legitimacy of the stakeholder's views regarding an issue at hand (Innes and Booher 2010) to reach a logical conclusion.

Several collaborative approaches have been progressively designed, applied and analysed as effective decision-making techniques for stakeholders to reach a consensus regarding complex issues in diverse contexts (Aas et al. 2005). For example, collaborative rationality is being demonstrated by the European Commission's "a white paper" on governance, in which collaboration is included with accountability, coherence, openness and effectiveness, as ideologies of good governance (European Commission 2001). Also, in the domains of sustainable development, collaborative approaches include focus group interviews, expert participatory interviews, consultative forums, stakeholder's workshops, consensus forums, sustainability negotiations, regulatory negotiations, deliberative interviews, policy simulation exercises, etc. (Derak et al. 2017; Nguyen et al. 2019; Van Den Hove 2006).

The adaptive reuse idea is a sustainable technique that implies changing the original use of an existing building (Aigwi et al. 2018; Douglas 2006) while retaining its original structure and fabric (Bullen and Love 2009), to extend the building's useful life (Mansfield 2002). Most complex adaptive reuse problems call for joint strategies among different stakeholders with varied interests, to work together for the realisation of shared satisfying outcomes. The role of collaboration in an adaptive reuse decision-making process seeks to improve the process to achieve a common outcome that is agreed by all stakeholders involved.

Accordingly, collaboration involves a constructive exploration of the viewpoints of different stakeholders involved in a decision-making process, and a collective search for solutions that would go beyond their narrow visualisation of what is possible (Ansell and Gash 2008; Gray 1989). Decision-making through collaboration addresses these problems by creating a shared understanding of the underlying problems including ways to tackle them (Innes and Booher 2010; Mayer et al. 2005). Additionally, the introduction of a collaboration process for the resolution of conflicting interests among adaptive reuse stakeholders could be crucial in the transformation of adversarial interactions into mutually acceptable outcomes. For that reason, 
the interests of all stakeholders involved in the decision-making process will be equally and fairly represented (Bond 2011).

However, while collaborative approaches are being recognised as a critical element of sustainable development goals (Van Den Hove 2006), intense conflicts of interests often exist over adaptive reuse issues (Aigwi et al. 2019b). Consequently, the concept of collaboration through the inclusion of stakeholder diversified interests and engagement has not been so prevalent in the adaptive reuse decision-making context (Wilson 2016). This paper, therefore, examines the roles of the relevant stakeholders in an adaptive reuse decision-making process, and the collaborative rationality that exists among them. The specific objectives are to: 1) characterise the stakeholders involved in the adaptive reuse decision-making process; and 2) investigate how the collaborative rationality can be effectively integrated into the decisionmaking process.

\section{Characterisation of Adaptive Reuse Stakeholders}

Adaptive reuse stakeholders (or "actors") are persons who devote their knowledge, interests, resources and time into adaptive reuse development plans. For this study, these persons are participants involved in a provincial town centre regeneration strategy in New Zealand, using the adaptive reuse approach as a sustainable development tool for the redevelopment of old and vacant historical buildings (Aigwi et al. 2018; Yakubu et al. 2017). They include building owners, developers, building professionals, heritage officers, local council officers, planners, legal representatives, etc. It is practically unavoidable to lack cooperation among these stakeholders while working on adaptive reuse elements such as economic and environmental sustainability, socio-cultural aspects, seismic resilience, heritage preservation through energy conservation (Elsorady 2017), and historical building usability aspects. Nevertheless, weak communication and cooperation among the key adaptive reuse actors could result in the loss of time and money (Miles et al. 2015). Moreover, besides some financial, logistics and design related issues posed to the adaptive reuse process, conflicting motives, interests and expectations among the key actors are also sneaky challenges (Cullingworth and Caves 2013). These challenges could serve as undermining detriments to using adaptive reuse as a viable approach for the redevelopment of disappearing urban areas (Aigwi et al. 2019a; Cullingworth and Caves 2013). It is therefore essential to define and characterise the roles of key players involved in an adaptive reuse decision-making process. Who are they, and why? For this paper, these stakeholders are classified under four main stakeholder groups based on their different interests regarding adaptive reuse (Misırlısoy and Günçe 2016): "investors”, "producers", "regulators", and "users".

\section{Investors}

The "investors" in an adaptive reuse decision-making process could be private historical building owners, funding organisations, government, tenants, etc. The standpoint of "investors" regarding adaptive reuse is normally pragmatic and business-oriented (Stipe 2003). The ultimate motivation for participating in an adaptive reuse project is often financially influenced. They tend to be more concerned about both the return on investment from implementing the adaptive reuse project and also the well-being of the "users" and the community (Stipe 2003). They are the risk bearers, hence they usually critically weigh the 
potentials of reusing an existing building to make a significant profit (or at least to break-even), before venturing into such projects. Before investing in an adaptive reuse project, "investors" usually try to determine what type of financial incentives are available to them. They also try to carefully understand the regulations that accompany these incentives.

Furthermore, the most common scenario experienced by the "investor" is the uncertainty regarding which stakeholder group would benefit the most after investing in an adaptive reuse project (Rypkema and Wiehagen 2000). In the United States for example, a number of investment incentives (i.e., federal rehabilitation tax credits, public grants, local property tax abatement through rate reliefs and deferment, revolving funds, and low interest loan pools) are made available by the government, to attract capital from potential "investors" (Rypkema and Wiehagen 2000). In New Zealand, potential adaptive reuse "investors" do not have access to significant incentives at the national level due to the absence of a central heritage credit scheme that rewards investors for redeveloping their buildings in a sustainable manner (Aigwi et al 2019a; Robert 2013). However, only regulatory incentives are provided to 'investors" by local authorities in the form of consent fee waivers, historic heritage rates relief, district plan regulatory incentives, and heritage-related grants (Robert 2013). There are also non-regulatory incentives for "investors" such as insurance rebates, urban strategy, events and promotion, tax relief through tax depreciation, heritage loans and grants, public-private partnerships, etc., at the local level (Robert 2013). Additionally, tenants of adapted historical buildings do not get any form of incentives through tax credits for choosing such sites. Although, the procedure for acquiring these incentives is typically cumbersome, "investors" often acknowledge that without adequate and readily accessible incentives, an adaptive reuse project will be too challenging to actualise (Bond 2011). However, this is outside the scope of this research.

\section{Producers}

The "producer" stakeholder group entail all participants in the main preparation and actualisation of an adaptive reuse decision-making process. They are made up of building professionals who could vary for different projects. The building professionals that fall under this category include engineers, architects, heritage restoration experts, quantity surveyors, designers, building contractors, etc. Producers are usually hired by investors after a decision for an existing building's new use has been established due to their expertise. The primary responsibility of the "producer" is to continuously ensure the feasibility of an adaptive reuse project while ensuring the right composition of the project's implementation team (Gratz 2007). The "producers" usually orchestrate the adaptive reuse process by bearing most of the risks from other stakeholder groups. They play a vital role in forming a "fabric of civilisation" through determining a community's aesthetic, health, and functional character (Peiser and Frej 2003). They are also responsible for keeping an adaptive reuse project afloat (Miles et al. 2015). According to Bond (2011), "producers" are often concerned about the timing, clarity, and closure of a particular project before embarking on it. The timing of an adaptive reuse project relates to the certainty and speed at which the project will be completed and readily available in the market. Whereas clarity involves the certainty and clarity of a project's design and redevelopment procedure, closure describes the project's advancement after it has been cleared by both regulatory and community review processes (Howe 2003).

Most "producers" prefer demolition and rebuild to trying to salvage an obsolete historical building through adaptive reuse (Yakubu et al. 2017). They feel the process of converting an old historical building into functional spaces for both commercial and residential tenants is 
discouraging. Hence they often get frustrated from trying to maintain standard heritage procedures during negotiations with heritage authorities (Trujillo 2011). They also believe that the adaptive reuse process is time consuming, complicated, and more expensive when compared to demolition and rebuilding. These opinions could be true in most cases (Trujillo 2011). Moreover, the "producers" get more confused especially when they are unsure of the heritage preservation agency they must work with (i.e., at the local, state or national level), during the redevelopment process. This becomes a problem because of the varying viewpoints of these agencies on how best to conserve a heritage building through adaptive reuse.

Take an instance, where the heritage preservation agencies at both local and national levels have equal jurisdiction over an adaptive reuse task. Accordingly, in New Zealand, development plans for historical buildings are approved at the national level only when national heritage preservation incentives have been awarded for that project (Heritage New Zealand Pouhere Taonga 2017). The "producer" also must abide by local building regulations and approval by the local historic heritage board. In situations like this, the "producer" is frustrated due to the loss of time and money while waiting for these agencies, who are demanding different treatments for the heritage features of the adaptive reuse project, to reach a compromise (Bond 2011). Additionally, in some cases it becomes difficult for members of a separate heritage review board to reach an agreement within the board regarding a most suitable preservation approach, let alone working together with a "producer" team for the actualisation of an adaptive reuse project.

Additionally, the "producers" often make every effort to achieve flexibility in an adaptive reuse project, for promoting innovation and creativity in the adaptive reuse design. On the other hand, too much compromise in an adaptive reuse project could result in a fuzzy project, and eventually, a possible financial failure. Apart from financial gains, the most significant challenge from the "producers" standpoint regarding adaptive reuse, remains to create a balance between the design expectation of the "producer" group, the "regulators" including heritage preservationists, and the prospective "users".

\section{Regulators}

The "regulators" are typically government representatives at both local and national levels, with the role of enacting rules and ensuring that the "producers" maintain strict compliance with relevant regulatory procedures during the adaptive reuse process. Such regulations include; building regulations, health and safety regulations, heritage regulations, planning and zoning regulations, etc. Moreover, "regulators are usually responsible for granting building consents, managing the review of historical designs, and enforcing zoning. They usually act as either information providers or development facilitators during adaptive reuse procedures.

According to (Mason 2009), the expectations of "regulators" regarding the success of an adaptive reuse project is that a project can only be considered successful if it helps accomplish its economic, socio-cultural, environmental and functional goals of providing a sustainable regeneration of an area (Mason 2009). The "regulators" who are directly involved with "producers" during the design review, consent approval and zoning phases, for instance, believe that "producers" could be annoyingly too pushy with their proposed redevelopment strategies (Bond 2011), hence, not necessarily concerned about compliance to laid down rules. Typically, "regulators" are not exclusively invested in the direct or indirect benefits from an adaptive reuse project, but rather, their focus is on enforcing the relevant rules. Furthermore, "regulators" are increasingly being faced with the challenge of monitoring "producers" trying 
to by-pass historic design review processes, as well as not conforming to current building standards (Rypkema 2008). Additionally, from a critical perspective, "regulators" believe the adaptive reuse process for the redevelopment of historical buildings is both complicated and unnecessarily more time-consuming (Gratz and Mintz 2000; Rypkema 2008).

\section{Users}

The "user" stakeholder group could be members of the community, passers-by, original users (i.e., existing tenants of an adapted historical building's original function), or contextual users (i.e., potential or future tenants of an adapted building) (Bond 2011). "Users" provide enhanced strategies for an adapted building's new use by representing demand either directly or indirectly through implementing a functional use of the building. Although the contribution of the "user" stakeholder category is very crucial to an adaptive reuse process, they are often ignored during decision-making. "Users" are more concerned about the aesthetic and economic viability of an adapted building's new function in accommodating the changing demand from its context. Also, "users" usually expect adapted buildings to be reversible to accommodate new needs when existing needs are no longer viable in the future.

\section{Effectiveness of Collaborative Rationality}

Collaborative strategies are focused on balancing diverse interests among different stakeholders to achieve more constructive outcomes rather than destructive ones (Ball et al. 2000). While constructive outcomes promote the viable solution and enhanced communication and relationships between relevant stakeholders, destructive outcomes usually foster mistrust, coercion and animosity (Innes and Booher 2010). Most adaptive reuse decision-making processes involve the contribution and cooperation of a diverse range of stakeholders (Miller and Buys 2008). However, the cause of conflict among stakeholders in an adaptive reuse decision-making process remains the inability to engage all stakeholders' interests through direct dialogue (Innes and Booher 2010). Besides, the collaborative process necessitates the expertise and interdependency of various stakeholders, right from a project's conception phase through its design, construction, completion, and functional phases (Miles et al. 2015). This kind of interdependency could arise in the process of a building owner/developer gaining building permits from the local council, or building professionals (i.e., Architects, Engineers, Quantity surveyors, etc.) consulting with local or regional heritage preservation officers, in ensuring that regulatory standards for the conservation of historic buildings are incorporated into the redevelopment plans of the buildings.

The Habermas' theory based on the inter-subjective social phenomena principles, proposes a model of interactive rationality that recognises an inseparable link between communication and the social world (Tuler et al. 2017; Van Den Hove 2006). Hence, building on Habermas theory to achieve a successful decision-making outcome, the following key essentials are proposed to be integrated into the design of a collaborative adaptive reuse decision-making process:

- Emphasis on a common interest - where different adaptive reuse stakeholders strive to achieve a common goal rather than simply adjusting their diverse interests 
- Transparency - the perceptions, orientations and values of each stakeholder's interests are clear and open to the critique of others.

- Ideal speech situation - a situation whereby only the natural vigour of the finest argument counts. Also, there are no external restrictions and deliberate behaviour of the stakeholders in this situation.

- Consistency in stakeholders' beliefs and actions - each adaptive reuse stakeholder endeavours to stand by what they have argued and justify their beliefs and actions with rationality that is consistent.

A major criticism of Haberman's work is that most models developed based on this theory often place too much emphasis on consensus, hence, disregarding the process of negotiation (Leeuwis 2000). Nevertheless, Van Den Hove (2006) argues that since Haberman's collaboration model contributes some powerful principles employed in the design of collaborative processes, it should not be disallowed, but preferably be combined with a negotiation model.

\section{Conceptual Framework Development and Validation}

An adaptive reuse project prioritisation framework was developed and validated using a focus group workshop to select an optimal historical building alternative for adaptive reuse project intervention in a New Zealand provincial town centre (Aigwi et al. 2019b). The focus group workshop was conducted with relevant stakeholders representing different portfolio and professional backgrounds regarding adaptive reuse (i.e., users, investors, producers and regulators).

To ensure effective stakeholder participation in an adaptive decision-making process, this study enabled the development of a conceptual framework for the integration of collaboration into the adaptive reuse decision-making process including the key essentials of collaboration: (i) emphasis of common interest; (ii) transparency; (iii) ideal speech situation; and (iv) consistency in stakeholder's belief and actions (see Fig. 1).

A reflection on the agreements among the stakeholders during the weighting and scoring process of the of the study by Aigwi et al. (2019), showed that the agreements among the stakeholders were more likely reached through compromise than consensus, although some form of negotiations existed in-between. This finding is consistent with a similar study conducted by Van Den Hove (2006). Besides, while the attribution of equal weights to sets of alternative options may reduce any potential social conflicts that may arise within a stakeholder group, the actors of that group have to agree on a preferred choice during the ranking process by reaching a consensus (Munda 2004).

Still, some stakeholders might take advantage of the adaptive reuse decision-making system and try to manipulate its collaborative process by pushing their interests. This could be a possible risk of integrating the collaborative approach into existing adaptive reuse decisionmaking techniques. Accordingly, a transparent collaborative process with well-defined procedures tends to reduce such risks (Brocklesby 2009; Le Menestrel and Van Wassenhove 2004).

\section{Implications for Consensus, Negotiation or Compromise}

Stakeholders involved in a decision-making process through collaboration usually attain mutual conclusion to deliberated issues by consensus (Ball et al. 2000). In an adaptive reuse 


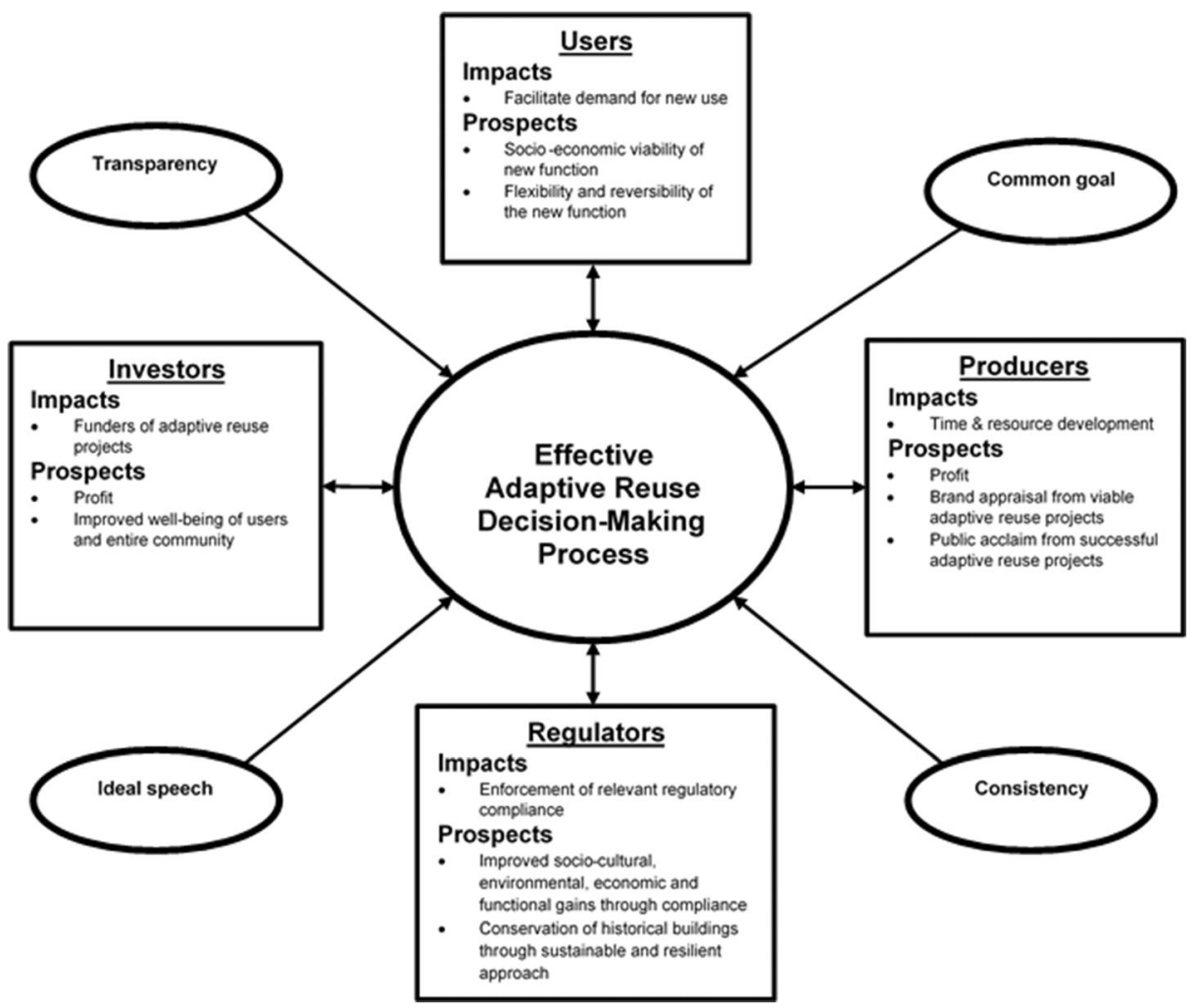

Fig. 1 Conceptual framework for an effective adaptive reuse decision-making process

decision-making context, consensus may not necessarily denote a preferred alternative or unanimous consent given by all relevant stakeholders, but instead, a decision supported by all. According to Innes and Booher (2010), a consensus is reached when about $90 \%$ of all stakeholders involved in a decision-making process is in support of a decision. Although the process of developing consensus could be time-consuming (Ball et al. 2000), it is essential for a vibrant collaboration among stakeholders in an adaptive reuse decision-making process. However, in past debates about distinguishing consensus from compromise, some argue that stakeholders cannot achieve real consensus without compromise (Ball et al. 2000).

A compromise could be described as a way to achieve consensus by adjusting and settling differences through agreement from all stakeholders involved in a decision-making process (Webster and McKechnie 1996). A successful compromise reached during an adaptive reuse decision-making process will determine if all stakeholders involved are satisfied with the final decision. Furthermore, the process of collaboration among adaptive reuse stakeholders involves sequences of negotiations (Bond 2011). The rationale for negotiation is that it brings about agreed adjustments in opinions through required commitments, rather than changing the fundamental opinions of the different stakeholders (Ball et al. 2000). Collaboration through negotiation could be applied to the adaptive reuse decision-making process context through problem-solving by principled negotiation (Fisher et al. 2011). Principled negotiation commits each stakeholder to recognise, accept and address the interests of other stakeholders constructively, for the advancement of their self-interests (Fisher et al. 2011). 


\section{Conclusion}

As the adaptive reuse concept develops, there are greater prospects of applying an understanding of the characterisation the stakeholders involved in an adaptive reuse decision-making process, and the effectiveness of collaboration among the relevant actors to construct stakeholder perspectives towards achieving more inclusive urban areas. Findings from this study identified and discussed four main stakeholder categories (i.e., investors, producers, regulators and users) in a typical adaptive reuse decision-making process. Also, the effectiveness of collaboration among the diverse stakeholders of an adaptive reuse decision-making process has been validated in a focus group workshop conducted by Aigwi et al. (2019b) through the incorporation of transparency, common goal, ideal speech, and consistency into the process. These findings imply that the effective collaboration that exists among characterised adaptive reuse stakeholders ranges between consensus-coordinated processes aimed at achieving a common interest and compromise-coordinated processes, towards adjusting the interests of the different stakeholders. Recognising the inevitable compromise dimension of collaboration among stakeholders could be useful in the design, implementation, and evaluation of adaptive reuse decision-making processes.

The dynamic involvement of stakeholders in an adaptive reuse decision-making process could increase public awareness on local concerns by delineating the opportunity for compromise, consensus, or agreement (Scolobig et al. 2016). Policy makers could be more guided on the expectations and needs of the public, thereby, enhancing consents (Dietz 2013) for the optimal adaptive reuse decisions. Accordingly, this study's conceptual framework aims to promote a better understanding of the characteristics of major adaptive reuse decision makers through: 1) active participation of the stakeholders for future adaptive reuse prioritisation exercises; 2) public consciousness and knowledge regarding adaptive reuse issues; 3 ) transparency and accountability among the stakeholders; 4) trust and organised networking among the stakeholders; 5) legitimacy and quality of adaptive reuse decisions.

Collaborative methodologies for sustainable decision-making outcomes are now stretching beyond the domains of theoretical focus and advocacy into that of real-life applications. Although a limitation of this research is that the conceptual framework has been tested in an adaptive reuse decision-making process in a New Zealand's provincial area only, it could be applied to other countries with similar decision-making contexts. Also, to mitigate the risk of manipulation of the adaptive reuse decision-making process, emphasis on a common goal, ideal speech, transparency and consistency among all stakeholders should be encouraged. This study, therefore, recommends that the effectiveness and quality of an optimal adaptive reuse decision-making solution could be improved by incorporating the proposed conceptual framework into future adaptive reuse projects.

Acknowledgements The authors wish to express gratitude to all participants of the focus group workshop for their huge contributions to the study. This paper was (partially) supported by QuakeCoRE, a New Zealand Tertiary Education Commission-funded Centre. This is QuakeCoRE number 0558

\section{References}

Aas C, Ladkin A, Fletcher J (2005) Stakeholder collaboration and heritage management. Ann Tour Res 32(1): $28-48$

Aigwi IE, Egbelakin T, Ingham J (2018) Efficacy of adaptive reuse for the redevelopment of underutilised historical buildings: Towards the regeneration of New Zealand's provincial town centres. International Journal of Building Pathology and Adaptation 36(4):385-407 
Aigwi IE, Phipps R, Ingham J, Filippova O (2019a) Urban transformation trajectories of New Zealand's earliest cities undergoing decline: Identifying links to the newly enforced Building (Earthquake-Prone b Buildings) Amendment Act 2016. Paper presented at the 43rd Australasian Universities Building Education Association (AUBEA) Conference, 6-8 November, Noosa QLD, Australia.

Aigwi IE, Egbelakin T, Ingham J, Phipps R, Rotimi J, Filippova O (2019b) A performance-based framework to prioritise underutilised historical buildings for adaptive reuse interventions in New Zealand. Sustain Cities Soc 48:101547. https://doi.org/10.1016/j.scs.2019.101547

Ansell C, Gash A (2008) Collaborative governance in theory and practice. J Public Adm Res Theory 18(4):543571

Ball A, Rebori M, Singletary L (2000) Introduction to collaborative process. Managing Natural Resource Disputes - No. 1. Retrieved 06/02 2018 from http://www.unce.unr.edu/publications/files/nr/other/fs9984.pdf

Bond C (2011) Adaptive reuse: explaining collaborations within a complex process. Department of Planning, Public Policy \& Management, University of Oregon

Brocklesby J (2009) Ethics beyond the model: how social dynamics can interfere with ethical practice in operational research/management science. Omega 37(6):1073-1082

Bullen PA, Love PE (2009) Residential regeneration and adaptive reuse: learning from the experiences of Los Angeles. Struct Surv 27(5):351-360

Cullingworth JB, Caves R (2013) Planning in the USA: policies, issues, and processes. Routledge

Derak M, Cortina J, Taiqui L (2017) Integration of stakeholder choices and multi-criteria analysis to support land use planning in semiarid areas. Land Use Policy 64:414-428

Dietz T (2013) Bringing values and deliberation to science communication. Proc Natl Acad Sci USA 110(supplement 3):14081-14087

Douglas J (2006) Building adaptation, 2nd edn. Routledge, London

Elsorady D (2017) Sustainability and Conserved Energy Value of Heritage Buildings. Renewable Energy and Sustainable Development 3(1):104-117.

European Commission (2001) European governance. A white paper. COM (2001), 428, 25

Fisher R, Ury WL, Patton B (2011) Getting to yes: Negotiating agreement without giving in. Penguin

Gratz RB (2007) Reports from the edge: the vacant-building syndrome. Next American City

Gratz RB, Mintz N (2000) Cities back from the edge: new life for downtown. Wiley

Gray B (1989) Collaboration: finding common ground for multiparty problems. Jossey-Bass Inc., San Francisco

Heritage New Zealand Pouhere Taonga (2017) National heritage preservation incentive fund. Retrieved from http://www.heritage.org.nz/protecting-heritage/national-heritage-preservation-incentive-fund

Howe KW (2003) Private sector involvement in historic preservation. A Richer Heritage: Historic Preservation in the Twenty-First Century, pp 279-311

Innes JE, Booher DE (2010) Planning with complexity: an introduction to collaborative rationality for public policy. Routledge

Le Menestrel M, Van Wassenhove LN (2004) Ethics outside, within, or beyond OR models? Eur J Oper Res 153(2): $477-484$

Leeuwis C (2000) Reconceptualizing participation for sustainable rural development: towards a negotiation approach. Dev Chang 31(5):931-959

Mansfield JR (2002) What's in a name? Complexities in the definition of "refurbishment". Prop Manag 20(1):23-30

Mason R (2009) Reclaiming the history of places. Local Planning: Contemporary Principles and Practice, pp $127-133$

Mayer IS, Van Bueren EM, Bots PW, Van Der Voort H, Seijdel R (2005) Collaborative decisionmaking for sustainable urban renewal projects: a simulation-gaming approach. Environment and Planning B: planning and design 32(3):403-423

Miles ME, Netherton LM, Schmitz A (2015) Real estate development : principles and process, 5th edn. Urban Land Institute, Washington DC

Miller E, Buys L (2008) Retrofitting commercial office buildings for sustainability: tenants' perspectives. J Prop Invest Financ 26(6):552-561

Mısırlısoy D, Günçe K (2016) Adaptive reuse strategies for heritage buildings: a holistic approach. Sustain Cities Soc 26:91-98

Munda G (2004) Social multi-criteria evaluation: methodological foundations and operational consequences. Eur J Oper Res 158(3):662-677

Nguyen PT, Wells S, Nguyen N (2019) A systemic indicators framework for sustainable rural community development. Syst Pract Action Res 32(3):335-352

Peiser RB, Frej AB (2003) Professional real estate development: the ULI guide to the business. ULI-the Urban Land Institute

Robert M (2013) Incentives for historic heritage toolkit - sustainable Management of Historic Heritage Guidance Series. Wellington, New Zealand Historic Places Trust Pouhere Taonga (NZHPT) 
Rypkema D (2008) Historic preservation and sustainable development. Lecture given at New Brunswick University, New Brunswick, Canada

Rypkema D, Wiehagen K (2000) Dollars and sense of historic preservation. The economic benefits of preserving Philadelphia's past. National Trust for Historic Preservation, Washington DC

Scolobig A, Thompson M, Linnerooth-Bayer J (2016) Compromise not consensus: designing a participatory process for landslide risk mitigation. Nat Hazards 81(1):45-68

Stipe RE (2003) A richer heritage: historic preservation in the twenty-first century. Univ of North Carolina Press Trujillo R (2011) Adaptive reuse: preservation through innovation. University of Kentucky, Lexington

Tuler SP, Dow K, Webler T, Whitehead J (2017) Learning through participatory modeling: reflections on what it means and how it is measured. In: Environmental modeling with stakeholders. Springer, pp 25-45

Van Den Hove S (2006) Between consensus and compromise: acknowledging the negotiation dimension in participatory approaches. Land Use Policy 23(1):10-17

Webster N, McKechnie JL (1996) Webster's new universal unabridged dictionary. Dorset \& Baber

Wilson KJ (2016) Exploring the role of design in sustainable adaptive reuse of built heritage. (PhD Thesis by publication), Queensland University of Technology, Q1, Australia

Yakubu IE, Egbelakin T, Dizhur D, Ingham J, Sungho Park K, Phipps R (2017) Why are older inner-city buildings vacant? Implications for town centre regeneration. J Urban Regen Renew 11(1):44-59

Publisher's Note Springer Nature remains neutral with regard to jurisdictional claims in published maps and institutional affiliations. 